\title{
Relationship between self-esteem and loneliness among university students living in hostels
}

Ishaq, Ghulam

Department of Psychology, University Sargodha, Pakistan (gishaq786@yahoo.com)

Solomon, Vicar

Institute of Applied Psychology, University of The Punjab, Pakistan (waqarsolomon@ gmail.com)

Khan, Omar

Department of Psychology, University Sargodha, Pakistan (ozebkhan@gmail.com)

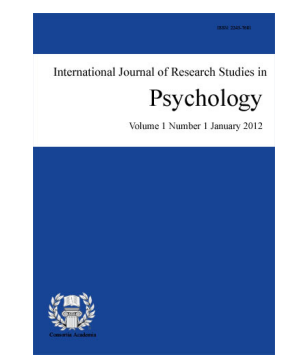

ISSN: 2243-7681 Online ISSN: 2243-769X

OPEN ACCESS

\section{Abstract}

The present study was intended to explore the relationship between self-esteem and loneliness among University Hostel Living students. It was hypothesized that there would be a negative correlation between self-esteem and loneliness. The sample of this study was comprised of $(\mathrm{N}=400)$ university students whose age ranging from 18 year to 24 year and living in hostels. Sample was drawn from different Universities from Punjab, Pakistan which consisted of almost equal numbers of males $(n=198)$ and females $(n=202)$ students. Data was collected through survey method. Self-esteem was measured through Rosenberg's Self- esteems scale (Rosenberg, 1965) and loneliness was measured by University of California and Los Angeles loneliness scale. Pearson bivariate correlation showed that there was significant negative correlation $\left(\mathrm{r}=-.57^{*} p<.001\right)$ between self-esteem and loneliness. Independent sample t-test showed that there was non-significance difference of self-esteem and loneliness among males and females students.

Keywords: self-esteem; loneliness; gender; university; hostel students 


\section{Relationship between self-esteem and loneliness among university students living in hostels}

\section{Introduction}

Loneliness and self-esteem both are social-psychological construct. Loneliness is a serious issue in students (Marja, Satu, \& Kaarina, 2013). Loneliness may be defined as "a state that reflects an individual's own perception of deficiencies in his or her network of social associations" (Russell, Cutrona, Rose, \& Yurko, 1984). Self-esteem clears as feelings of self-worth and self-respect (Rosenberg, 1965).

\subsection{Loneliness}

There are different theories existing by which we can explain loneliness but one of the most suitable and most popular theories which explain loneliness, is cognitive discrepancy theory. According to this theory loneliness is a discrepancy between one's own desired and achieved levels of desired either in quality or quantity of social relations. Loneliness is related to subjective feelings (Peplau \& Perlman, 1982), because it is the experience felt by particular individuals. Human being comes into the world alone, works through all life alone and finally goes away from this world alone. Managing with this, tolerating it and learning how to straighten his own existence with some degree of grace and contentment is all about the human condition. On the other hand, existentialist theorists claim that human beings might be said to keenly involve each other and the universe as they connect and create, while loneliness is just the feeling of being cut off from this process.

Loneliness is also defined as "A social situation experienced by the individual as one where there is an unpleasant or inadmissible lack of certain relationships. This includes situations, in which the number of existing relationships is smaller than the considered desirable number as well as situations where the intimacy one wishes for has not been realized" (De Jong Gieruela, 1987).

Loneliness is a distressing, painful experience that humans want to avoid. Most people are probably going to have a significant experience of loneliness some time in their lives (Rokach \& Brock, 1997). Oshagan and Allen (1992) reported that the prevalence of loneliness in the general population has been estimated to range from $15 \%$ to $28 \%$. Unfortunately, researchers emphasized that loneliness is a more prevalent and serious problem among university students. Moreover, many students have reported experiencing loneliness (Wiseman, Guttfreund, \& Lurie, 1995). Knox, Vail-Smith, and Zusman (2007) found that 25.9\% of college male students and $16.7 \%$ of college female students had severe loneliness feelings. In a more recent study, Özdemir and Tuncay (2008) found in their study on Turkish college students that $60.2 \%$ of the participants experienced loneliness. The findings also showed high means of loneliness (45.49). It is not surprising that college students develop feelings of loneliness because the university life is a transitional period from high school to college and from being adolescent to being an adult and from home to hostel. The new environment demands abandoning the old social network and exerting a great effort to seek and build a new close and social relationship with others, which may lead to the experience of loneliness.

There are several estimates and indicators of loneliness. It has been estimated that approximately 60 million people in the US or $20 \%$ of the total population, feel lonely. Another study found that $12 \%$ of Americans have no one with whom to spend free time or to discuss important matters. Almost same percentage can be expected in Pakistani population and most of which would be students living in hostels.

\subsection{Self-esteem}

Self-esteem is a construct discussed in social sciences, especially in psychology and sociology to show a 
person's general emotional assessment of his individual worth (Hewitt, 2009). Self-esteem has also been defined as the overall feeling of self-worth or acceptability (generalized feelings of self-acceptance), goodness and self-respect (Crocker \& Major, 1989; Coopersmith, 1967; Wylie, 1979; Rosenberg, 1965). People have a basic need for self-esteem (Epstein, 1973).

In recent articles self-esteem defined as features of self-evaluation, the amount to which one's judge himself in a constructive or deleterious and respectable or depraved. Self-esteem can be said as to how far one consider and escalate the overall own self. Self-esteem is divided into different dimension as cognitive skills, physical skills, or social skills. The development of self-esteem is from along with our experiences from the interaction with the social environment. In this we are focus on this type of self-esteem i.e. development self-esteem (Triantoro, 2015).

Self-esteem develops in the early stages, remains fairly constant over time, and is relatively immune to change (Campbell, 1990). Self-esteem is also known as a way for a person to remain dominant in relationships (Barkow, 1980). Trait self-esteem appeared to be related to the degree to which participants felt accepted by specific people in their lives, but not to the degree to which participants thought those individuals perceived them as dominant. Acceptance and dominance appeared to have independent effects on self-esteem. The ethological perspective suggests that self-esteem is an adaptation that has evolved for the purpose of maintaining dominance in relationships (Barkow, 1980).

Self-esteem can also be defined as how confidently individuals assess themselves (Baumeister, 2008). Self-esteem is described as a link between one's own ideal self and one's own actual, serving off of positive behaviors (Leary, 1999). It awakens an individual's own sense of worth, in which an individual values, supports, appreciates, awards, or likes himself. Self-esteem helps in motivating people to achieve their goals, high self-esteem leading to coping in situations and low self-esteem leading to avoidance (Leary, 1999).

Individual who have low scores on self-esteem have more trouble when facing problems or obstacles. They demonstrate low handling tactics and competencies. This trouble is due to the two sorts of negative self-perception: first, people with low self-esteem have a higher level of fear when facing threats/problems compared with those who have high self-esteem. Second, people with low self-esteem regard themselves as person who lacks adequate skills to deal with a problem. As a result, they are less likely to take preventive action and have a fatalistic belief that they cannot do anything to prevent a bad problem in their lives. Their belief in their ability to solve the problem is low, so they tend to withdraw from the problem and not deal with the responsibility.

\section{Methodology}

\subsection{Participants}

The sample $(N=400)$ of the study obtained from the selected universities from Punjab, contained almost equal number of male Students $(n=198)$ and female Students $(n=202)$. The age range of the participants was 18 to 24 years $(\mathrm{M}=20.58, \mathrm{SD}=1.88)$ and studying in university in any undergraduate program and living in hostel.

\subsection{Measures}

Three self-report instruments that provided best operationalization of variables of the present study according to theoretical ground of the variables were select for the present study. The instruments, which have been use across different culture and having no risk of cultural biasness, were also considered for the selection. It was also ensure that selected scales have good psychometric properties. The details of these instruments are as follows:

Rosenberg's Self- esteems scale 
Ishaq, G., Solomon, V., \& Khan, O.

$>\quad$ University of California and Los Angeles loneliness scale

$>$ Demographic information and informed consent

Rosenberg's Self-esteems scale - is used to measure self-esteem. The scale consists of 10 items and does not has any subscales. It has a four-point likert scale i.e., "strongly agree", "agree", "disagree", and "strongly disagree". For the positively worded items the scoring of 4 is assigned to "strongly agree", 3 to "agree", and 2 to "disagree" and 1 assigned to "strongly disagree". Only five items of the scale (i.e. 3, 5, 8, 9 and 10) are reversely scored (strongly agree $=1$, agree $=2$, disagree $=3$, and strongly disagree $=4$ ). The score of the scale ranges from 10 to 40 , where high scores on this scale mean high self-esteem whereas low scores indicate low self-esteem (Rosenberg, 1965).

University of California and Los Angeles (UCLA) loneliness scale - having 20 items to measure loneliness. It has 4 points Likert scale i.e. O ("I often feel this way"), S ("I sometimes feel this way"), R ("I rarely feel this way"), N ("I never feel this way"). For the positively worded items $1=\mathrm{O}$ ("I often feel this way") $2=\mathrm{S}$ ("I sometimes feel this way") $3=\mathrm{R}$ ("I rarely feel this way") and $4=\mathrm{N}$ ("I never feel this way"). Some item of the scale (i.e. $1,5,6,9,10,15,16,19,20$ ) are reverse scored as $1=\mathrm{N}$ ("I never feel this way") $2=\mathrm{R}$ ("I rarely feel this way") $3=$ S ("I sometimes feel this way") 4= O ("I often feel this way"). The score of the scale ranges from 20 to 80 . Coefficient ranges from .89 to .94 and test-retest reliability over a 1-year period $(\mathrm{r}=.73)$.

Demographic measures - The first items of the survey tool were assessing demographic information. Age was measure as a continuous variable. Gender was a categorical variable assesse as male and female.

\subsection{Procedure}

In order to gather the responses, students were individually and face to face contacted and then they were informed about the impartial of the study by signing informed consent. They were ascertained that their seclusion and secrecy will be preserved after amassment of data. Afterward, scales were given to take replications of students. They were appreciated for their participation after taking response and in the terminus, research participants were thanked for the valuable co-operation. All participants were treated in accordance with the APA code of ethics.

\section{Results}

The obtained data were subjected to statistical analyses through SPSS version 21. Descriptive statistics and alpha coefficients of reliability were computed for each of the scales. A correlations analysis was undertaken for testing the proposed hypotheses of the present study.

\section{Table 1}

Psychometric property of study variables $(N=400)$

\begin{tabular}{|c|c|c|c|c|c|c|c|c|}
\hline \multirow[b]{2}{*}{ Variables } & \multirow[b]{2}{*}{$N$} & \multirow[b]{2}{*}{$M$} & \multirow[b]{2}{*}{$S D$} & \multirow[b]{2}{*}{ Alpha } & \multicolumn{2}{|c|}{ Range } & \multirow[b]{2}{*}{ Skewness } & \multirow[b]{2}{*}{ Kurtosis } \\
\hline & & & & & Potential & Actual & & \\
\hline Loneliness & 400 & 56.60 & 11.06 & .73 & $20-80$ & $23-80$ & .08 & .52 \\
\hline Self esteem & 400 & 27.05 & 3.21 & .68 & $10-40$ & $15-40$ & .22 & 1.3 \\
\hline
\end{tabular}

Table 1 shows psychometric properties of study variables. The reliability analysis indicates that the reliability coefficient of loneliness is .79 and reliability coefficient of self-esteem scale is .68 which indicates satisfactory internal consistency. The values of skewness and kurtosis for loneliness are less than 1 which indicates that univariate normality is not problematic. The values of skewness for self-esteem are less than 1 and for kurtosis is more than 1 .

The Pearson correlation between self-esteem and loneliness, indicate that loneliness has significant negative correlation with self-esteem $(r=-.57, p<.001)$. 
Relationship between self-esteem and loneliness among university students living in hostels

Table 2

Mean and standard deviation and t-value for male and female among study variable $(N=400$.)

\begin{tabular}{lccccccc}
\hline & \multicolumn{2}{c}{ Female $(n=202)$} & \multicolumn{2}{c}{ Male $(n=198)$} & & \multicolumn{2}{c}{ Cohen's $d$} \\
\cline { 2 - 5 } Variables & $M$ & $S D$ & $M$ & $S D$ & $t(398)$ & $P$ & 0.04 \\
Loneliness & 56.70 & 11.01 & 56.20 & 11.13 & -.46 & .39 & .68 \\
Self esteem & 26.93 & 3.08 & 27.20 & 3.35 & .85 & .68 & 0.07 \\
\hline
\end{tabular}

Table 2 shows mean standard deviation and $t$-values for male and female students on loneliness and self-esteem. Results indicate non-significant mean differences on loneliness with $t(398)=-.46, p>.05)$. The findings show that female scored high on loneliness $(M=56.70, p>.05)$ as compared to male $(M=56.20$, $p>.05)$. Results also indicate also mean differences on self-esteem with $t(398)=.85, p>.05$. The findings show that male students $(M=27.20, p>.05)$ scored higher on self-esteem as compared to female students $(M=26.93$, $p>.05)$.

\section{Discussions}

The current study was pioneering work on the relationship between loneliness and self-esteem among most important population i.e. hostel living students. It was quite surprising to find out that studies focusing on the relationship between these two variables was quite scarce albeit the theoretical plausible link between them. Our findings elucidate that the both variable i.e. self-esteem and loneliness have significant relationship, which supported our research hypothesis. This finding was buttressed by (McWhirter, 1997) who found that self-esteem had a negative correlation with loneliness. The findings of the study showed that loneliness might play an imperative role in reducing self-esteem among university students living in hostels. Loneliness among university students living in hostels was related with lessened self-esteem. These relations are in treaty with many earlier discoveries. The negative correlation between self-esteem and loneliness can interpret as (Hoffmann, Powlishta, $\&$ White, 2004) renowned that those who have low level of self-esteem are most vulnerable to feel criticized and rejected by someone from their society.

Low self-confidence and social skills required for starting and developing associations or relation, issues that are associated to loneliness. Low social skills influence individuals to feel lonely because of unsuccessful social relations that do not make positive reinforcement from the society (Gerson \& Perlman, 1979). The study was aimed to find gender differences in self-esteem and loneliness. The results showed that there is no significant difference in self-esteem and loneliness among males and females. These findings were supported by the previous studies that found no significant differences between males and females (Brage, Meredith, Ozdemir \& Tuncay, 2008; Woodward, 1993). The result shows that both male and female is affected same from hostel and that further affect same their self-esteem and feelings of lone.

\section{Conclusion and Suggestions}

The present study was aimed to examine the relationship between relationship between loneliness and self-esteem among university hostel living students. This opens new avenues of research for the implications of psychology of self in social psychology in terms of the dynamic processes involved in his relationships which is most important factors for his academic achievements.

From the results of the study it can be concluded that gender difference did not contributed to loneliness and self-esteem significantly. The findings also show that there is significant negative co relation between self-esteem and loneliness, indicating that the features of students living in hostels of the universities are not unique, but in fact loneliness and self-esteem in them are same as that which has been observed in general population of other countries. The findings point out the importance of introducing the treatment and prevention programs and find ways to reduce the levels of loneliness to increase their self-esteem among university students living in hostels. 
The overall results of the present study lead to the conclusion that enhancing studentse self-esteem buffer the effect on their feelings of lone and vice versa. Studying many courses at a time in university and living in hostel is an involute task that is associated with solicitousness and feelings of uneasiness, obstacles, self-doubt and apprehension. Additionally edifiers and student counseling associations services have to deal with students who come to class not only with diverse capabilities and aptitudes but additionally with a range of home town i.e. subculture boundaries. Teachers and student counseling association services should be helped in pedagogical preparation programs to be aware of the concept of loneliness, so that they can help better address loneliness in medical universities and engender better educational situations for their students.

Despite its scientific rigor, the present study involves certain limitations. Firstly, while assessing relationship between loneliness and self-esteem among university hostel living students, it was not possible to control all factors which may influence one's self-esteem or characteristic style of loneliness; therefore, the inferences of the current study are theoretically grounded. Hostel type i.e. private hostel, campus hostel or rental residency, situational demands, personal dispositions of the hostel living students, home town, and characteristics of those where he or she is living with may have significant impact on the relationship. Future studies should incorporate these variables for exploring their mediating or moderating role between the variables of the present study.

Moreover, relationship found in the present study may have been inflated owing to mono-operation and mono-method bias (Shadish, Cook, \& Campbell, 2001) because data were collected through self-report measures. The participants of the current study were university students, who may not be a representative sample of the general population. Therefore, one should be cautious while generalizing the present findings. Finally, the variables of the present study should be investigated in population of executives in various occupational groups whose job description typically require them to make professional decisions quite frequently. In the future researches more valid results can be obtained by controlling family system and past experience of students living in the hostels.

\section{References}

Barkow, J. (1980). Prestige and self-esteem: A biosocial interpretation. In D. R. Omark, F. F. Strayer, \& D. G. Freedman (Eds.), Dominance relations: An ethological view of human conflict and social interaction (pp. 319-332). New York: Garland.

Baumeister, R. F., \& Bushman, B. (2008). Social psychology and human nature (1st ed.). Belmont, CA: Wadsworth.

Brage, D., Meredith, W., \& Woodward, J. (1993). Correlates of loneliness among Midwestern adolescents. Adolescence, 28, 685-693.

Campell, J. D. (1990). Self-esteem and the clarity of the self-concept. Journal of Personality and Social Psychology, 59(3), 538-549. https://doi.org/10.1037/0022-3514.59.3.538

Coopersmith, S. (1967). The antecedents of self-esteem. San Francisco, CA: Freeman.

De Jong Gierveld, J. (1987). Developing and testing a model of loneliness. Journal of Personality and Social Psychology, 53(1), 119-128. https://doi.org/10.1037/0022-3514.53.1.119

Epstein, S. (1973). The self-concept revisited or a theory of a theory. American Psychologist, 5, 404-416. https://doi.org/10.1037/h0034679

Hewitt, J. P. (2009). Oxford handbook of positive psychology. Oxford University Press.

Knox, D. K., Vail-Smith, K., \& Zusman, M. (2007). The lonely college male. International Journal of Men's Health, 6(3), 273-279. https://doi.org/10.3149/jmh.0603.273

Leary, M. R. (1999). Making sense of self-esteem. Current Directions in Psychological Science, 8(1), 32-35. https://doi.org/10.1111/1467-8721.00008

Marja, V., Satu, U., \& Kaarina, M. (2013). College students' experiences of and coping with loneliness possibilities of peer support. International Journal of Research Studies in Education, 2(4), 13-28.

McWhirter, B. T. (1997). Loneliness, learned resourcefulness, and self-esteem in college students. Journal of Counseling and Development, 75, 460-469. https://doi.org/10.1002/j.1556-6676.1997.tb02362.x 
Relationship between self-esteem and loneliness among university students living in hostels

Oshagan, H., \& Allen, R. L. (1992). Three loneliness scales: An assessment of other measurement properties. Journal of Personality Assessment, 59, 380-409. https://doi.org/10.1207/s15327752jpa5902_13

Özdemir, U., \& Tuncay, T. (2008). Correlates of loneliness among university students. Child and Adolescent Psychiatry and Mental Health, 2(29), 1-6. https://doi.org/10.1186/1753-2000-2-29

Peplau, L. A., \& Perlman, D. (Eds.) (1982). Loneliness: A sourcebook of current theory, research and therapy. New York: Wiley.

Rokach, A., \& Brock, H. (1997). Loneliness and the effects of life changes. The Journal of Psychology, 131, 284-298. https://doi.org/10.1080/00223989709603515

Rosenberg, M. (1965). Society and the adolescent self-image. Princeton, NJ: Princeton University Press. https://doi.org/10.1515/9781400876136

Russell, D., Cutrona, C., Rose, J., \& Yurko, K. (1984). Social and emotional loneliness: An examination of Weiss's typology of loneliness. Journal of Personality and Social Psychology, 46, 1313-1321. https://doi.org/10.1037/0022-3514.46.6.1313

Shadish, W. R., Cook, T. D., \& Campbell, D. T. (2001). Experimental and quasi-experimental designs for generalized causal inference. Boston: Houghton- Mifflin.

Triantoro, S. (2015). Are daily spiritual experiences, self-esteem, and family harmony predictors of cyber bullying among high school student? International Journal of Research Studies in Psychology, 4(3), 23-33.

Wiseman, H., Guttfreund, D. G., \& Lurie, I. (1995). Gender differences in loneliness and depression of university students seeking counselling. British Journal of Guidance \& Counselling, 23(2), 231-243.

https://doi.org/10.1080/03069889508253008 
Ishaq, G., Solomon, V., \& Khan, O. 